FERNÁNDEZ, José Manuel, “La Ley de Violencia Intrafamiliar, el bien jurídico protegido y el patriarcado: un estudio preliminar".

Polit. Crim. Vol. 14, № 28 (Diciembre 2019), Art. 14, pp. $492-519$

[http://politcrim.com/wp-content/uploads/2019/12/Vol14N28A14.pdf]

\title{
La Ley de Violencia Intrafamiliar, el bien jurídico protegido y el patriarcado: un estudio preliminar
}

\section{The Law of Domestic Violence, the protected legal good and patriarchy: a preliminary study}

José Manuel Fernandez Ruiz

Abogado, Licenciado en Ciencias Jurídicas y Sociales. Universidad de Chile. Chile. LLM

University of Toronto. Canadá. PhD law Glasgow University. Reino Unido

Profesor de Derecho Penal y Teoría del Derecho, Universidad Alberto Hurtado

jmfernandez@uahurtado.cl

\section{Resumen}

El ensayo tiene por objetivo examinar el bien jurídico protegido por la Ley de Violencia Intrafamiliar a la luz del significado del término patriarcado. El ensayo aborda el objetivo recurriendo a otras disciplinas, como la teoría social y la filosofía, para poder enriquecer la discusión jurídico-penal sobre la ley 20.066. Si bien este es un estudio preliminar, donde no es posible abordar toda la complejidad que involucra comprender este cuerpo legal bajo la noción de patriarcado, si se establecen ciertas conclusiones substantivas sobre el bien jurídico protegido, y se proponen ciertas líneas de investigación que prometen ser fructíferas en esta materia. El ensayo inicia distinguiendo la diferencia entre género y sexo. Sobre esta base propone una comprensión del patriarcado como injusticia estructural, lo que se manifiesta en la privación o restricción desigual de ciertas opciones fundamentales para la vida buena de las personas. Luego, se critican ciertas propuestas sobre el bien jurídico protegido por la ley 20.066, y finalmente se formula una propuesta que incorpora el término patriarcado en la justificación de las formas de conducta criminalizadas por la ley.

Palabras clave: violencia intrafamiliar, género, patriarcado, control coercitivo

\begin{abstract}
The essay aims to examine the legal good protected by the Law of Domestic Violence 20.066 in light of the meaning of the term patriarchy. The essay addresses the objective by resorting to other disciplines, such as social theory and philosophy, to enrich the criminal law discussion on law 20.066. Although this is a preliminary study, where it is not possible to address all the complexity involved in understanding Law 20.066 under the notion of patriarchy, certain substantive conclusions are established about the protected legal good, and certain lines of research are proposed that promise to be fruitful in this matter. The work begins by distinguishing the difference between gender and sex. On this basis, it proposes an understanding of patriarchy as a structural injustice, which manifests itself in the unequal deprivation or restriction of certain fundamental options for the good life of the
\end{abstract}


people. Then, certain proposals about the legally protected good of Law 20.066 are criticized, and finally a proposal is made that incorporates the term patriarchy in the justification of the forms of conduct criminalized by the law.

Key words: domestic violence, gender, patriarchy, coercive control

\section{Introducción}

Recientemente en Chile las mujeres han politizado ciertas demandas buscando alcanzar un sentido de igualdad más profundo y han cambiado el horizonte político de sus derechos. Este nuevo empoderamiento de las mujeres sobre su derecho a ser tratadas como iguales ha modificado la percepción ciudadana sobre la justicia de estos reclamos, sino que también en la sociedad civil este empoderamiento ha tenido un importante impacto (piénsese por un lado en la renuncia de Carlos Carmona a su casa de estudios, y la salida de Fernando Villegas de la televisión abierta). En este cambiante contexto político aparece cotidianamente el uso del término "patriarcado" para describir a nuestra sociedad y sus instituciones, sean públicas o privadas, y a sus miembros. Si bien es cierto que no hay, y no es esperable que exista un consenso sobre el significado y las implicaciones del uso de este término, sí parece necesario un concepto más preciso si pretendemos utilizarlo para evaluar ciertas instituciones y prácticas. Esto no es únicamente relevante para el ámbito académico, sino que la práctica política también requiere cierta precisión en su pretensión de persuadir a su audiencia. En el ámbito de la filosofía del lenguaje, el término "patriarcado" aparece no solamente como un término descriptivo de ciertas relaciones humanas, sino que implícitamente parece conllevar una carga evaluativa que se usa normalmente para valorar ciertas prácticas. Desde esta perspectiva el término "patriarcado" puede considerarse como un concepto ético grueso o un thick concept ${ }^{1}$, porque tiene tanto un componente evaluativo como un componente descriptivo. Ciertamente, considerar que ciertos casos de violencia doméstica son "patriarcales", que es lo que voy a considerar en este ensayo, no necesariamente involucra describir estas interacciones de una determinada manera, sino que evaluarlas negativamente. Cuando usamos este término para describir estas interacciones, ¿qué es precisamente lo que estamos haciendo?

El presente ensayo no tiene por objetivo responder directamente a ciertas preguntas generales sobre la relación entre el Derecho Penal y el patriarcado, sino el objetivo mucho menos ambicioso: ofrecer algunos planteamientos preliminares para comprender de una manera alternativa, pero más plausible, la criminalización de ciertas conductas constitutivas de delitos al interior de la familia. En este sentido puede considerarse que responde indirectamente, y en cierta medida, a dichas preguntas generales. El objeto de la investigación, sin embargo, consiste en examinar ciertos aspectos penales de la Ley de Violencia Intrafamiliar chilena (en adelante, Ley VIF) y, más específicamente, formula la pregunta si el concepto de patriarcado cumple o no alguna función en la justificación de la criminalización de ciertas interacciones familiares. La motivación fundamental que orienta este trabajo es la creencia que la existencia de ciertas desigualdades estructurales en la

\footnotetext{
${ }^{1}$ VAYRYNEN, Raimo, "Thick Ethical Concepts", en: ZALTA, Edward, (ed.) The Stanford Encyclopedia of Philosophy, 2017, en: https://plato.stanford.edu/entries/thick-ethical-concepts/ [visitado el 12.12.2018].
} 
sociedad moderna, en particular la chilena, impactan desproporcionadamente en algunas personas. Más específicamente, me parece que la plausibilidad del concepto de patriarcado consiste precisamente en su potencial explicativo de ciertas desigualdades estructurales que generan consecuencias adversas para los intereses y derechos de las personas. Este no es un enfoque completamente nuevo, porque este es básicamente el acercamiento filosófico político feminista al concepto de patriarcado ${ }^{2}$, y que ha sido objeto de intenso debate en la teoría social ${ }^{3}$, y en las ciencias empíricas. La evidencia, sin embargo, apunta a demostrar que ciertos fenómenos de violencia pueden ser explicados en la noción de patriarcado ${ }^{4}$. $\mathrm{Si}$ bien no explica toda la violencia que se produce al interior de una sociedad, si parece explicar ciertos tipos de violencia que se produce en ciertas áreas de la vida familiar.

Me parece que no es plausible ignorar estas investigaciones de teoría social, empíricas y filosóficas para la comprensión de la violencia al interior de la familia. No es plausible ignorar estas investigaciones porque estas han respondido precisamente a los movimientos sociales y políticos que han inspirado modificaciones legales importantes como la Ley VIF, movimientos que aspiraban a la formación de una sociedad más justa y que centraban su crítica en la existencia de una sociedad patriarcal.

Uno de los primeros estudios en la materia en Chile, del año $1989^{5}$, demostraba la reticencia de las propias mujeres a denunciar la violencia por considerar que se trataba de un tema "privado". Es decir, la ausencia de interés por denunciar estos hechos de violencia por parte de las víctimas se basaba en una concepción de la familia como una esfera privada en la que no cabía la intervención del Estado. La explicación a este fenómeno, por ende, no se basaba puramente en la auto-comprensión de las víctimas, sino en la comprensión de dicha violencia en el ámbito familiar. En efecto, son factores estructurales referentes a la concepción de la familia los que permiten comprender la violencia de manera diferente y son estas razones "estructurales" para no denunciar, las que han ciertamente han cambiado hoy. Desde este punto de vista, el reconocimiento de los derechos de las mujeres al interior de la familia y el interés en encontrarse libre de violencia, ha significado relocalizar las relaciones familiares trasladándolas desde el ámbito privado hacia el ámbito público. ${ }^{6}$ Este tránsito, argumentaré, ha recepcionado de alguna manera la idea que cierta violencia cometida al interior de la familia se explica, en parte, por la existencia de una sociedad patriarcal. Considerando todo lo anterior, no parece plausible interpretar la Ley VIF dejando de lado el rol que este concepto cumple para comprender este cuerpo legal y sus disposiciones particulares.

\footnotetext{
${ }^{2}$ MIKKOLA, Mari, The Wrong of Injustice: Dehumanization and Its Role in Feminist Philosophy, Oxford: Oxford University Press, 2016, passim.

${ }^{3}$ Véase en general, ACKER, Joan, “The Problem With Patriarchy”, Sociology, no 23 (1989), pp. 235-240.

${ }^{4}$ JOHNSON, Michael; LEONE, Janel, "The Differential Effects of Intimate Terrorism and Situational Couple Violence: Findings From the National Violence Against Women Survey", Journal of Family Issues, no 26 (2005), pp. 322-349.

${ }^{5}$ MOLTEDO, Cecilia; SILVA, Clotilde; ORELLANA, Silva; Estudio Sobre Violencia Doméstica en Mujeres Pobladoras Chilenas, Santiago: CUSO, 1989, citado por CASAS, Lidia; VARGAS, Macarena, "La respuesta estatal a la violencia intrafamiliar", Revista de Derecho, nº 24 (2011), p. 134.

${ }^{6}$ SACK, Emily, "Battered Women and the State: The Struggle for the Future of Domestic Violence Policy", Wisconsin Law Review, $\mathrm{n}^{\circ} 6$ (2004), pp. 1658-1739; en general véase SCHNEIDER, Elizabeth, Battered women and feminist lawmaking, New Heaven: Yale University Press, 2000.
} 
El trabajo está organizado en cinco secciones. En la primera sección examino el contraste entre lo que se entiende por género y sexo desde una perspectiva general, explicando su relevancia política, moral y legal. En la segunda, introduzco el término "patriarcal" para designar ciertas injusticias relacionadas con la descripción de una sociedad como patriarcal y explico cómo estas injusticias tienen como consecuencia la exposición de ciertas personas a sufrir diversas formas de violencia en las relaciones familiares de manera desigual. En la tercera, propongo una interpretación de lo que cabe entender por violencia patriarcal, la que basaré en ciertos estudios empíricos que desagregan los diferentes tipos de violencia que experimentan las víctimas en el contexto de la vida familiar. En la cuarta, examino las concepciones principales que se han planteado por la doctrina chilena para comprender el bien jurídico del delito protegido por el art. 14 de la Ley VIF. En la quinta sección, y final, propongo una interpretación particular del bien jurídico protegido por el tipo descrito en el art. 14 y la defiendo de ciertos contra-contra-argumentos y posiciones alternativas. Aunque las conclusiones de este trabajo no son definitivas, porque constituye un acercamiento preliminar, estas identifican razones para creer que el término patriarcado es importante para la debida comprensión de la ley y sus disposiciones.

\section{Que es el género}

El género en la filosofía y la teoría social moderna se entiende mejor en la forma de un contraste: el contraste entre el uso de los términos "sexo" y "género"7 El término "sexo" normalmente se usa para clasificar a los seres humanos en masculinos y femeninos, fundamentalmente de acuerdo a ciertos criterios biológicos ${ }^{8}$. Los criterios más tradicionales consisten en diferenciar el sexo masculino y el sexo femenino de acuerdo a ciertos tamaños y formas anatómicas del cuerpo. El término "sexo", entonces, se usa para clasificar los seres humanos en dos categorías como una distinción binaria que viene biológicamente determinada. Esto no sólo tiene consecuencias importantes sobre como las personas autocomprenden su carácter y potencial de cambio, sino que también tiene efectos que van más allá del mero individuo. En efecto, si partimos de la premisa que ser mujer o ser un hombre no es una construcción social, entonces se promueve y fortalece una visión de las instituciones sociales como construidas independientemente de nuestras prácticas, y por ende, como si no tuvieran ningún efecto sustantivo en como los individuos forman y rechazan sus identidades. A esta conclusión, poco plausible por lo demás, se arriba desde la premisa que las identidades sexuales vienen definidas biológicamente.

\footnotetext{
${ }^{7}$ En cuanto a la historia del término "género", este es de acuñación reciente. Se debe a un trabajo de un psicoanalista de EEUU llamado Robert Stoller, quien estudiando la transexualidad en los años 60, comenzó a utilizar el término "sexo" para la adscripción de características biológicas, y el término "género" para la adscripción de masculinidad y femineidad de acuerdo a consideraciones sociales. Este contraste entre los dos términos permitió a Stoller abrir una nueva línea de investigación: el estudio de la constitución del género en términos de prácticas sociales, legales, y culturales, y no exclusivamente a través del método de las ciencias naturales suministradas por la biología, véase STOLLER, Robert, The Development of Masculinity and Femininity, London: Karnac Books, 1968.

${ }^{8}$ MIKKOLA, Mari, "Feminist Perspectives on Sex and Gender", en: ZALTA, Edward, (ed.) The Stanford Encyclopedia of Philosophy, 2017, en: https://plato.stanford.edu/cgibin/encyclopedia/archinfo.cgi?entry=feminism-gender [visitado el 12.12.2018].
} 
La conclusión que el determinismo biológico es implausible parecería incorrecta si es que consideráramos plausible que los niños nacen con una cierta atracción al color azul y las niñas al color rosado. Como indica Fausto-Sterling 9 , psicólogos y biólogos se esfuerzan por encontrar las causas de la diferencia sexual en las hormonas y los genes, pero no consideran el hecho más básico que las preferencias se forman en una combinación de factores socioculturales y biológicos. El término "género", en contraste con el término "sexo", se erige sobre premisas fundamentalmente diferentes. El término "género" toma como base clasificatoria los procesos sociales de construcción social, de lo que se sigue que lo relevante para determinar el género no son factores causales reducibles a la biología de los individuos, sino las mismas prácticas sociales. Como afirma Butler ${ }^{10}$, el género es performativo, es una práctica social, y una práctica social normalmente no se organiza a través de criterios binarios. El concepto de género pretende rebatir la postura del determinismo "biológico" y sus implicancias. En particular, de acuerdo al término "género", las identidades, incluidas las identidades sexuales, son una construcción social en el sentido que nuestras prácticas culturales y sociales le dan sentido a nuestras propias identidades. En otras palabras, la clasificación entre lo femenino-masculino y otras clasificaciones, dependen de nuestras prácticas humanas y, por lo tanto, no vienen biológicamente determinadas. Las identidades se aprenden y se siguen, se aceptan y se rechazan.

Hasta el momento he seguido un acercamiento principalmente teórico y académico, aunque he descrito tímidamente algunas consecuencias que de ello se siguen. No obstante, este acercamiento tiene importantes consecuencias políticas, morales y legales, respecto a cómo se organiza políticamente una sociedad, cuáles son los principios de justicia en los que se cimienta su estructura y, en lo que a este ensayo interesa, qué es lo que se considera debe evaluarse negativamente, digno de reprobación social y por lo tanto como un objeto posible del Derecho Penal. Esto es así porque la visión del ser humano acorde al determinismo biológico ha sido determinante, en primer lugar, en el establecimiento del círculo de aquellos considerados aptos para disfrutar ciertos derechos políticos. Asumiéndose una perspectiva biológica para comprender la ciudadanía, y por ende, para la especificación de quienes tienen derecho a voz y voto, esta visión consideró en su momento que las mujeres no eran biológicamente aptas para deliberar con la "frialdad" que se requería para elegir representantes políticos. Esta doctrina biologicista ocultaba en la rigurosidad de la actividad científica una postura política que tendía evitar la disputa del poder político hasta ese entonces exclusivamente reservado a los hombres. Ciertamente, en la historia reciente del derecho al sufragio universal, solo hasta fechas relativamente recientes se estableció el derecho a voto para la mujer (en Suiza por ejemplo el derecho a voto para las mujeres solo fue concedido en todos los cantones recién en 1971), logro fundamentalmente alcanzado gracias a los movimientos y organizaciones feministas. Efectivamente, el sufragio universal

\footnotetext{
9 FAUSTO-STERLING, Anne, "Where does gender come from?", en: KIMMEL, Michael; ARONSON, Amy, (eds.) The Gendered Society Reader, New York and Oxford: Oxford University Press, 2017, pp. 3-4; en general véase FAUSTO-STERLING, Anne, Myths of Gender: Biological Theories About Women and Men, New York: BasicBooks, 1992.

${ }^{10}$ BUTLER, Judith, Gender Trouble: Feminism and the Subversion of Identity, London and New York: Routledge, 1990, pp. 23-35; ECKERT, Penelope; MCCONNELL, Ginet, Language and Gender, Cambridge: Cambridge University Press, 2003, p. 10.
} 
se entiende como resultado de lo que se denomina el movimiento social de la "primera ola feminista" $"$.

En segundo lugar, el determinismo biológico como doctrina sobre el "sexo" no ha sido solamente utilizado como fundamento para tomar ciertas medidas de carácter político, sino que más modernamente para evaluar las capacidades individuales de razonamiento moral. Lawrence Kohlberg desarrolló sus famosas etapas de "desarrollo moral" durante los años 70 y 80 , concluyendo que la mente humana normal desarrolla su razonamiento moral de manera secuencial, avanzando desde la moral pre-convencional, pasando por la moral convencional, hasta arribar a la adultez donde normalmente se alcanza el estadio postconvencional. En sus estudios, Kohlberg identificó diferencias en los puntajes de desarrollo moral alcanzado por hombres y mujeres, las que marcaban sistemáticamente por dejado del nivel post-convencional. Esta perspectiva aparece influenciada por el determinismo biológico que consideraría esperable estos resultados en atención a que las mujeres nacen con un potencial de desarrollo moral inferior al de los hombres. Al respecto, Carol Gilligan con posterioridad cuestionó las conclusiones de Kohlberg. Según Gilligan las mujeres marcaban sistemáticamente menos puntaje que los hombres no porque tuvieran un desarrollo moral inferior, sino porque la escala evaluaba de acuerdo a criterios no neutrales en favor de los hombres, como la justicia liberal de "responsabilidades y derechos individuales" $"$. Hoy se acepta en la psicología moral moderna ${ }^{13}$ que hay al menos dos formas de razonamiento moral, uno a la Kohlberg centrado en la justicia, y otro a la Gilligan, centrado en el cuidado.

En tercer lugar, el determinismo biológico impacta en cómo se ha diseñado y ha variado la estructura del Derecho Penal y el tipo de conductas que regula. Hasta hace no mucho tiempo, se consideraba que los hechos de violencia al interior de la familia no constituían actos merecedores de reprobación social y escrutinio público ${ }^{14}$. Por el contrario, se consideraba que la mujer debía ocupar ciertos roles sociales y familiares propios del ámbito privado y que esta esfera privada debía en principio quedar resguardada de la interferencia pública del Estado. En consecuencia, las interacciones familiares quedaron a cargo del padre de familia y, por lo tanto, al considerarse como un espacio reservado fuera del escrutinio público del Estado, la violencia intrafamiliar se resguardó de la intervención del Derecho Penal. Esta concepción de los roles de la mujer está indisputablemente influenciada por la creencia que las mujeres son mejores en la crianza de los niños y en la administración del hogar, como una aptitud que se origina en su naturaleza biológica. Hasta hace no mucho esta comprensión naturalizada de los roles sociales reforzaba la visión que lo que sucedía al interior de la familia no podía quedar bajo el escrutinio público. Como debería comenzar a quedar claro, luego de este breve examen de ejemplos políticos, morales y legales; las concepciones de género operan como parte de una concepción más

11 KROLOKKE, Charlotte; SORENSEN, Anne; Gender Communication Theories and Analyses: From Silence to Performance, London: SAGE, 2006, pp. 1-7.

${ }^{12}$ GILLIGAN, Carol, In a Different Voice: Psychological Theory and Women's Development, Cambridge Mass: Harvard University Press, 1993, pp. 19-20.

${ }^{13}$ JORGENSEN, Gunnar, “Kohlberg and Gilligan: duet or duel?", Journal of Moral Education, no 35 (2006), pp. 179-180.

${ }^{14}$ En Chile, incluso por las propias víctimas, véase el estudio de Moltedo citado por Lidia Casas citado en la nota al pie $n^{\circ} 5$. 
amplia de las personas y sus roles sociales, asignándoles, de acuerdo a diferentes descripciones, diferentes roles y con ellos la exposición a ciertos beneficios y daños.

Es cierto que la noción de sexo entendido como criterio biológico y de género como construcción social no son elementos aislados y que por lo tanto, posiblemente, no sean los únicos factores causales si se quiere, que expliquen la desigualdad y la violencia de género. Sin embargo, ambos forman parte de un "paradigma" cabe interpretar ciertas prácticas e institucionales sociales, y cuando se estructuran las prácticas bajo dicho entendimiento, todos participan de alguna manera u otra en su mantención o reproducción. Si se acepta que las mujeres no son inferiores biológicamente a los hombres en sus capacidades perceptivas, cognitivas y afectivas, y esta es la comprensión que se encuentra en la ciudadanía, entonces aparecen preguntas que no aparecerían si la descripción del determinismo biológico fuera verdadera. En efecto, si fuera verdadera la tesis del determinismo biológico, entonces no parecería incorrecto negarle derechos políticos a la mujer, o considerarla incapaz de juzgar de manera moralmente correcta y no necesariamente incorrecto negar el escrutinio público de los hechos de violencia al interior de la familia cometidos por el pater familias. Ciertamente, un mundo estructurado política, moral y legalmente de acuerdo a valores dominantes históricamente masculinos tiende, sin duda, a describir las prácticas sociales de un modo (aparentemente) neutral, de modo que no aparecen controversias en el plano de la política, la moral y el Derecho. Esto, como se verá en la siguiente sección, es importante porque el término género permite describir ciertas prácticas e instituciones que no serían posibles sin ella. Estas descripciones permiten comprender las razones por la cuales deberíamos evaluar algunas de estas prácticas e interacciones de manera negativa. En particular, el término género permite describir las "injusticias de género" como fenómenos que deberían ser objeto de escrutinio político, moral y legal.

\section{Lo injusto de la sociedad patriarcal}

Ahora bien, pareciera que de considerar la corrección del concepto de género para entender nuestras identidades sociales debería seguirse una determinada posición de moralidad política sobre lo correcto o incorrecto, sin embargo, esto no es así. Del hecho de aceptar la noción de género y construcción social no se sigue necesariamente ninguna conclusión normativa o moral. Es decir, por el simple hecho de entender que el género es socialmente construido, y que tiene consecuencias políticas y legales importantes para la sociedad y sus individuos, no se sigue ninguna conclusión moral determinada. Sin embargo, el enfoque de género sí posibilita una posición moral crítica y, desde luego, una posición política y legal crítica, porque es gracias a esta noción que podemos concebir que exista algo así como un arreglo social patriarcal. Sin la noción de género no sería posible describir una sociedad patriarcal, en la medida que pretendemos entender el término patriarcado como un concepto éticamente grueso. Como hemos visto, entender el patriarcado como tal implica considerar que tiene elementos descriptivos y evaluativos. Por lo tanto, sin el concepto de género, el componente descriptivo ya no haría referencia a procesos sociales de construcción social. Esto tendría una consecuencia importante: al no poder entenderse ciertos arreglos sociales

${ }^{15}$ En general, véase KUHN, Thomas, La Estructura de las Revoluciones Científicas, Trad.: CONTÍN, Agustín, México: Fondo de Cultura Económica, 2013, passim. 
injustos como el producto de procesos de construcción social, tampoco podríamos comprenderlos como procesos sociales que de alguna manera están bajo el control de las personas y por los cuales ellos y ellas pueden hacerse responsables. Sin la noción de género, sólo queda la explicación determinista de la biología, y entonces, ¿quién es responsable?, ¿nuestras hormonas?, ¿nuestros genes?

Parece plausible, como lo he sostenido, adoptar la noción de género y, entonces, cabe explorar la noción de patriarcado con mayor profundidad. Si bien no dispongo de espacio suficiente para detallar una explicación completa del origen y elementos de la noción de patriarcado, esto no parece necesario en atención al objetivo que persigo con este trabajo, cual es ofrecer un planteamiento preliminar al estudio del patriarcado en la criminalización de las relaciones de familia bajo la regulación de la Ley de VIF. Me referiré brevemente en esta sección a algunos aspectos históricos que son relevantes para entender el patriarcado y que me permitirá demostrar con mayor claridad las bases del componente evaluativo; las injusticias a que da lugar el patriarcado.

Comencemos con la revisión histórica, la que caracteriza la posición de la mujer en la sociedad como una posición de desventaja y desigual. Más específicamente, podemos caracterizar su posición como de subordinación y opresión bajo la comprensión de género, es decir, que no podemos explicar dicha posición únicamente con información sobre la biología del hombre y de la mujer. Cabe notar que esta posición de la mujer como subordinada y oprimida no comienza con el origen del capitalismo, como a menudo erradamente se cree, sino que está ya presente en la época feudal. El patriarcado, de acuerdo a algunas especialistas en las ciencias históricas, es un hecho histórico de larga data, previo incluso a la edad media ${ }^{16}$. Sin embargo, pondré atención a las épocas más recientes ya que el modelo de Estado chileno, clave para entender la situación de la mujer en el Chile hoy, sienta sus bases en el modelo de Estado europeo de la modernidad, el que se encuentra fuertemente influido por el modelo previo de organización política y económica, el modelo feudal. Aquí aparece, al final de la sociedad feudal, y por ende en el tránsito a la sociedad moderna, una clara asociación que luego sigue existiendo en el origen de la modernidad y durante ella, entre el acceso de la mujer a la economía y al poder político. Es decir, la posición de desventaja de la mujer y que marca su subordinación y opresión, vendría explicada en alguna medida por la relación entre el acceso de la mujer a la economía y al poder político.

De acuerdo a numerosos estudios histórico-sociales a fines de la edad feudal en el mundo europeo la mujer no es parte del mercado productivo. La mujer se encuentra relegada a la economía doméstica, dentro de la familia. Si es que la mujer llega a ingresar al mercado lo hace bajo un estatus social de miseria, reducida a realizar actividades económicas que solo tienen por fin combatir la pobreza ${ }^{17}$. Las mujeres de clase media, en cambio, siguen el estatus del hombre de la familia: el del padre si no están casadas, o el del marido si lo están. En este modelo de organización social, aquellos que participan en el mercado formalmente

\footnotetext{
${ }^{16}$ Lerner, localiza temporalmente el patriarcado en las civilizaciones previas a la cultura romana, véase LERNER, Geda, The Creation of Patriarchy, New York and Oxford: Oxford University Press, 1986.

${ }^{17}$ HOWELL, Martha, Women, Production and Patriarchy in Late Medieval Cities, Chicago and London: Chicago University Press, 1986, pp. 174-183.
} 
y con cierto estatus tienen acceso al mismo tiempo al poder político ${ }^{18}$. Aparece entonces una descripción de la sociedad feudal que puede denominarse como "patriarcal": un modelo de sociedad que reserva exclusivamente al hombre el acceso al mercado y a la política, un modelo en que la autoridad y la fuerza es ejercida fundamentalmente por el hombre. Este modelo de sociedad y posterior organización del Estado, perdura en el modelo de organización capitalista de la economía. Ciertamente, la economía se altera fundamentalmente con la revolución industrial, y muchas mujeres pasan a formar parte del "mercado de trabajo" del naciente capitalismo europeo, pero la diferente organización económica no cambia fundamentalmente la comprensión de la ciudadanía en términos del ejercicio de derechos políticos por parte de una clase reducida de personas, como se sabe, una clase correspondiente a hombres de cierto nivel socio-económico.

En suma, nuestra sociedad al tomar prestado el modelo de Estado y organización política y económica europea, no sólo importa el modelo de la ilustración, sino también el modelo feudal de organización social y política. En efecto, pese a las declaraciones de los movimientos independentistas del siglo XIX, así como en Francia y en EEUU en el siglo previo, lo cierto es que el voto y la capacidad para organizar política y económicamente la sociedad no fue estructurada universalmente ${ }^{19}$. Nuevamente, sólo ciertos hombres de un particular estatus socio-económico ${ }^{20}$ tienen el derecho a participar y establecer la estructura de la organización política y económica del estado. El estado independiente chileno comienza de manera similar a sus "padres" europeos. Se organiza una sociedad chilena con una estructura desigual de poder, originariamente unido a la economía y a la política, perpetuándose el establecimiento de una organización social en la que las mujeres continúan teniendo un estatus inferior. En otras palabras, de acuerdo al enfoque que se ha argumentado; por razones de género no se trata a todos como iguales. No es una sorpresa entonces que la subordinación y opresión de las mujeres todavía pueda atribuirse a este modelo de Estado. En efecto, este es precisamente el que diferentes corrientes de pensamiento feminista caracterizan y critican por estructurar el poder social, económico, cultural y moral en forma desigual. En otras palabras, tenemos a grandes rasgos la descripción de un Estado (y sociedad) patriarcal.

Bajo esta descripción aparece con mayor claridad el componente evaluativo del patriarcado, al que ya se hiciera alusión con los términos "opresión" y "subordinación". Es entonces en las implicancias de un Estado patriarcal donde podemos identificar el componente evaluativo del patriarcado. En otras palabras, en sus efectos sobre la justicia de las relaciones sociales, pues como ya afirmara, el patriarcado tiene como efecto fundamental el estructurar relaciones sociales en las que las mujeres resultan desaventajadas en relación a los hombres. Ya que la injusticia del patriarcado consiste en ciertas estructuras sociales, me parece acertada la comprensión de estas injusticias como desigualdades estructurales injustas. En palabras de Michelle Madden Dempsey:

\footnotetext{
${ }^{18}$ En general véase WIESNER-HANKS, Merry, Gender In History: Global Perspectives, Chichester: WileyBlackwell, 2010, Capítulo 6.

${ }^{19}$ Véase en Chile, ELTIT, Diamela, Crónica del Sufragio Femenino en Chile, Chile: Servicio Nacional de la Mujer, 1994.

${ }^{20}$ El igual que como ocurrió, previamente, en Francia, véase CAPALDI, Nicholas, "The Meaning of Equality", en: MACHAN, Tibor (ed.), Liberty and Equality, California: Hoover Institution Press, 2002, 1-35.
} 
“[...] el patriarcado es una desigualdad estructural injusta. Las desigualdades estructurales son funciones de las estructuras sociales, los 'conjuntos de reglas y principios que rigen las actividades en los diferentes ámbitos de la vida social'. Cuando las estructuras sociales sostienen o perpetúan la distribución desigual del poder social, pueden entenderse como desigualdades estructurales. Las desigualdades estructurales informan nuestra comprensión práctica con respecto a la forma en que funciona el mundo, al proporcionar un contexto para reconocer queé personas generalmente tienen el poder [... $]^{\text {,21 }}$

Esta sociedad patriarcal que organiza y distribuye poder en forma desigual tiene un efecto fundamental sobre las posibilidades que tienen algunas personas, en este caso las mujeres, para elegir la vida que quieren vivir. Es decir, tiene un efecto perjudicial fundamental en la elección de una vida autónoma y auténtica:

"El patriarcado limita sistemáticamente el acceso de las mujeres a las opciones que son fundamentales para el éxito de sus vidas. Se supondrá que limitar el acceso de una persona a opciones que son críticas para el éxito de su vida es algo incorrecto. Como las mujeres son personas, el patriarcado es, por lo tanto, incorrecto." 22

Esta sección ha perseguido entender cómo el Estado chileno, entre otros, se ha organizado y se organiza actualmente de forma desigual, tratando de mostrar cómo esta organización tiene consecuencias para el acceso a opciones fundamentales para que las personas puedan en igualdad de condiciones elegir qué vida quieren vivir. Como se trata de una concepción amplia este enfoque sobre lo incorrecto del patriarcado deja relativamente abierta la solución. Bien puede ser integrar a las mujeres, plenamente y en igualdad de condiciones a los hombres, al mundo de la economía de mercado. $\mathrm{O}$ bien, puede involucrar el rechazo a esta solución, posiblemente aduciendo como razón, que el capitalismo es esencialmente patriarcal y por ende justificando algún tipo de revolución. No pretendo naturalmente zanjar cuál podría ser la solución final a la estructuración de un Estado patriarcal, pero sí llamar la atención sobre la plausibilidad de caracterizarlo de esta manera. Cuatro proposiciones muestran lo productivo que es considerar el término patriarcado como fundamental para describir las relaciones sociales de hoy. Primero, se evita naturalizar las prácticas sociales. Segundo, se posibilita considerar a los seres humanos, sus actitudes, carácter, intenciones y prácticas sociales como los factores que contribuyen fundamentalmente a su organización política. Tercero, permite reconocer que tomando como base las prácticas de organización política, los seres humanos localizan a sus miembros en diferentes posiciones, algunas de privilegio y otras de opresión o sometimiento. Cuarto, permite comprender que uno de los factores fundamentales de cambio consiste precisamente en abordar de diferentes maneras las diferentes situaciones de las personas que mantienen dichas prácticas.

\footnotetext{
${ }^{21}$ DEMPSEY, Michelle Madden, Prosecuting Domestic Violence: A Philosophical Analysis, Oxford: Oxford University Press, 2009, p. 113.

${ }^{22}$ DEMPSEY, Prosecuting, cit. nota ${ }^{\circ} 21$, p. 141.
} 


\section{La violencia patriarcal}

En la sección precedente, siguiendo a Madden Dempsey, afirmé que el carácter injusto de la sociedad patriarcal radica en que genera desigualdades estructurales. Es decir, se trata de estructuras sociales, instituciones y grupos que generan desigualdades en el acceso a opciones fundamentales por razones de género. Si vinculamos lo injusto de la sociedad patriarcal a lo que cabe entender por violencia, parece precisarse una de las formas características a través de las cuales opera la sociedad patriarcal: se priva por razones de género de opciones fundamentales a través de la violencia. Es decir, siguiendo una influyente definición de violencia de la OMS 'el uso intencional de fuerza o poder físico y psicológico, amenazado o efectivo, contra uno mismo, contra otra persona o contra un grupo o comunidad, que resulta en o que tiene una alta probabilidad de resultar en lesiones, muerte, daño psicológico, mal desarrollo o privación ${ }^{23}$ constituye una pérdida de opciones fundamentales que la sociedad patriarcal distribuye desigualmente por razones de género. Tenemos entonces una definición de lo que se entiende por violencia patriarcal: es aquella pérdida de opciones fundamentales de la persona y que se produce a consecuencia de distintas formas de violencia que tienen su origen en la existencia de una sociedad patriarcal.

Esta conexión entre la pérdida de opciones fundamentales y la violencia que tiene su origen en una sociedad patriarcal es crucial, y es muchas veces pasada por alto. Quiero referirme ahora y brevemente a una concepción de la violencia inspirada en la existencia de una sociedad patriarcal, y que si bien parece en principio plausible, yerra en conectar la violencia que priva a las personas de sus opciones fundamentales con la existencia de una sociedad patriarcal. Examinar esta concepción es relevante, porque permite subrayar la existencia de un problema general de ciertas concepciones sobre la violencia (patriarcal) que no logran hacer visible que dicha violencia se explica por la existencia de una sociedad patriarcal. Es decir, estas concepciones ocultan precisamente lo que deberían poner de manifiesto: que se trata de violencia patriarcal. Para María Martín Sánchez la violencia de género:

"Constituye una agresión directa a la dignidad de la mujer, a la que se golpea -en su sentido más amplio- por el mero hecho de ser mujer. Más allá de la problemática social o jurídica que entraña, es una cuestión de derechos humanos, de violación de los derechos más elementales de la mujer, no por otra cosa que por ser mujer. No es "violencia" sin más, la violencia de género encarna un sentimiento, una actitud de dominación sobre la mujer, de exhibición de poder sobre ella como si fuera una mera posesión, una "cosa" de su propiedad. Es un ataque a los derechos humanos." ${ }^{24}$

Según mi parecer esta comprensión es a grandes rasgos acertada. Ciertamente esta comprensión considera correctamente que la violencia tiene un carácter colectivo: es una

\footnotetext{
23 World Health Organization (1999): "World report on violence and health", en: https://www.who.int/violence_injury_prevention/violence/world_report/en/full_en.pdf [visitado el 16.12.2019]

${ }^{24}$ MARTÍN SANCHEZ, María, "El género en la 'violencia afectiva': clave para un examen de constitucionalidad”, Estudios Constitucionales, n” 13 (2015), p. 204.
} 
actitud de dominación sobre la mujer. Destaca de esta comprensión que la violencia consiste en un estado mental de un determinado sujeto, un estado intencional o doloso. Destaca así mismo que el daño es entendido como violencia física. Todas estas propiedades, de hecho, ni si quiera parecen problemáticas para una comprensión liberal del Derecho Penal orientada a la regulación de hechos particularmente lesivos de los intereses individuales. Lo que si merece atención es el tipo de discurso que fundamenta la preocupación: se trata de una afectación de Derechos Humanos. En principio esta referencia no me parece problemática, en la medida que se considere a los Derechos Humanos como repositorio de valores más o menos universales, pero fundamentales para la justicia y la vida buena en una sociedad. No tener Derechos Humanos, o estar privado de ellos, sin duda constituye una pérdida de opciones valiosas que se destruyen como efecto de la sociedad patriarcal. Sin embargo, el recurso a los Derechos Humanos también involucra una comprensión demasiado estrecha de la violencia de género.

En efecto, define la violencia como una lesión de un Derecho Humano. El problema es que el lenguaje de los derechos es especialmente poco apto para poder caracterizar el fenómeno de la violencia patriarcal. Me parece que el problema fundamental del lenguaje de los Derechos Humanos es que individualiza el fenómeno de la violencia. Tener un derecho implica una relación tríadica ${ }^{25}$ : hay un titular de un derecho, hay un titular de un deber de respetar tal derecho y hay un Estado sujeto a proveer de los medios jurídicos necesarios para que, llegado el caso, el titular pueda requerir su protección frente al titular del deber. Como hemos visto, el fenómeno de la violencia de género no parece estar correctamente descrito como un fenómeno exclusivamente individual: la violencia tiene su origen en estructuras sociales injustas. Este carácter estructural de la violencia patriarcal no queda adecuadamente capturado por el lenguaje de los derechos. De esto se sigue una consecuencia importante. Si lo que define lo que es la violencia patriarcal es la consideración de un portador de un Derecho Humano individual, y esta se explica en la existencia de autor individual, se sigue que la solución pasa exclusivamente por corregir al autor individual.

Me parece que un enfoque como este no da cuenta del problema de la violencia que genera una sociedad patriarcal, no obstante nos informe sobre las concepciones de la vida buena y lo correcto que fundamentan la preocupación por la violencia a nivel institucional. Como dije más arriba, la privación de opciones fundamentales para las personas, como el no poder ejercer adecuadamente un derecho fundamental a consecuencia de la violencia de género, explica porque esta preocupación es importante. Ahora, si el objetivo es de alguna manera reducir o disminuir la sociedad patriarcal en cuanto genera violencia de género, pareciera mejor un enfoque más amplio que considere no sólo a la víctima y el ofensor, sino que englobe todo el contexto social, porque es precisamente dicho contexto el que muestra que dicha violencia viene explicada por las propiedades patriarcales de la sociedad. Lo que debe modificarse de manera sustancial es cómo nos relacionamos los unas/unos con otras/otros, y ello requiere de cambios profundos en como la sociedad está organizada. La dificultad no sólo radica en lo amplio, difuso y complejo del problema, sino si las

\footnotetext{
${ }^{25}$ ALEXY, Robert, Teoría de los Derechos Fundamentales, Madrid: Centro de Estudios Constitucionales, 1993, p. 201
} 
herramientas que estamos utilizando son idóneas para este fin. Si gran parte de la violencia que todos experimentamos hoy, es debido a la estructura de la sociedad patriarcal, entonces aparecen serias dudas sobre si el Derecho Penal está realmente capacitado para tomar parte en esta empresa de manera medianamente efectiva y de manera algo más que una intervención simbólica.

Hay una salida a este problema que pasa por definir un objeto más modesto y limitado para el Derecho Penal. Esta comprensión del papel del Derecho Penal es limitada y marginal, aunque no por esta razón cabe negar que sea crucial. Una adecuada limitación de la intervención del Derecho Penal supone, para los estudiosos del Derecho Penal, identificar que exista una situación cuya gravedad, tanto desde el punto de vista de la forma de la conducta, como desde el punto de vista de lo valioso de los intereses que están en juego, que haga tal intervención legítima. Esta posición coincide a grandes rasgos con ciertos estudios empíricos que distinguen varias clases de violencia en las relaciones familiares. Si bien el estudio que consideraré se restringe a los casos de violencia en las relaciones afectivas o íntimas, tiene la virtud de proponer una comprensión de esta violencia recurriendo a las teorías que la explican en la existencia de una sociedad patriarcal. Michael Johnson, en un estudio del 2005, distingue tres clases de violencia, sólo una de las cuales vendría explicada en la existencia de una sociedad patriarcal:

“[...] el terrorismo íntimo es violencia arraigada en un contexto de relaciones personales caracterizadas por un control coercitivo general. El terrorismo íntimo es la violencia a la que se refieren las teorías feministas, en la que un compañero usa la violencia y otras tácticas de control coercitivo para tratar de tomar el control general sobre su pareja. Johnson recurre a la teoría de género para argumentar que, aunque esa violencia de control coercitivo puede ser perpetrada por hombres o mujeres en relaciones heterosexuales o del mismo sexo, será más común en relaciones heterosexuales, donde es principalmente perpetrada por hombres... El segundo tipo de violencia en la pareja íntima, la resistencia violenta, surge cuando la víctima del terrorismo íntimo usa la violencia en respuesta a la violencia coercitiva controlador que usa su pareja. En las relaciones heterosexuales, la resistencia violenta es utilizada principalmente por las mujeres. El tercer tipo importante es la violencia situacional en pareja, que surge en el contexto de conflictos específicos en los que los argumentos se convierten en agresión verbal y, en última instancia, en violencia física. Johnson argumenta que la perpetración de violencia de pareja situacional es más o menos simétrica en cuanto al género y que es probable que ocurra tanto en personas del mismo sexo como en relaciones heterosexuales". 26

La propuesta teórica de Johnson es relevante porque demuestra que ciertos tipos de violencia responden a un cierto modelo de sociedad, rechazando que toda la violencia es producto de la sociedad patriarcal. Ahora bien, el estudio de Johnson es, sin embargo, insuficiente para identificar otras clases de hechos que si parecen ser producto de la

\footnotetext{
${ }^{26}$ JOHNSON Michael; LEONE, Janel; XU, Yili, "Intimate Terrorism and Situational Couple Violence in General Surveys: Ex-Spouses Required”, Violence Against Women, ${ }^{\circ} 20$ (2014), p. 187. Las cursivas en el texto son del original. Cabe señalar que Johnson en su primera articulación de la teoría diferenciaba entre dos situaciones de violencia, el terrorismo patriarcal y la violencia común de pareja, véase JOHNSON, Michael, "Patriarchal Terrorism and Common Couple Violence: Two Forms of Violence against Women, Journal of Marriage and Family", n 57 (1995), pp. 283-294. Con posterioridad diferencia las tres situaciones distintivas arriba indicadas.
} 
sociedad patriarcal, lo que no quita lo fundamental de sus aportes. Lo importante de su investigación es que enfatiza que lo fundamental en ciertos casos de violencia es que está dirigida a controlar a la pareja y que normalmente esta violencia desmesurada es ejercida por el hombre contra la mujer. Sin embargo, esto último es también parte del problema. Johnson caracteriza el terrorismo íntimo adicionalmente por el nivel de violencia que ejerce normalmente el hombre contra la mujer, concluyendo que por regla general es el hombre quien utiliza fuerza desmesurada en las relaciones íntimas. Evan Stark propone considerar no solamente el terrorismo íntimo como violencia que puede ser explicada por el patriarcado, sino que adicionalmente otra clase distintiva de violencia que no se caracteriza tanto por el nivel de fuerza empleada, sino por el tipo de finalidad que persigue: controlar a la pareja ${ }^{27}$. Como consecuencia, afirma Stark, también es posible encontrar violencia patriarcal en la violencia situacional. En el fondo plantea Stark, en la violencia situacional hay que distinguir entre violencia situacional propiamente y otra violencia que es utilizada para controlar a la pareja. Esto lleva a Stark a plantear que los casos de terrorismo íntimo que destacó Johnson y estos casos particulares de violencia situacional tienen caracteres comunes que sugieren un tratamiento conjunto. Stark propone, en consecuencia, sustituir la comprensión de terrorismo doméstico por control coercitivo. El control coercitivo, de acuerdo a Stark constituye una conducta que se despliega:

“[...] casi exclusivamente por los hombres para dominar a mujeres individuales a través del entrelazamiento del abuso físico repetido con tres tácticas igualmente importantes: intimidación, aislamiento y control. Las agresiones son una parte esencial de esta estrategia y con frecuencia es perjudicial y, a veces, fatal. Pero el daño principal que infligen los hombres abusivos es político, no físico, y refleja la privación de derechos y recursos que son críticos para la persona y la ciudadanía. Aunque el control coercitivo puede ser devastador psicológicamente, su dinámica clave implica un estado objetivo de subordinación y la resistencia de las mujeres para liberarse de la dominación. El derecho de las mujeres a utilizar cualquier medio disponible para liberarse del control coercitivo se deriva de la forma en que los hombres las usan para oprimirlas, no de los daños físicos o psicológicos inmediatos que pueden sufrir debido al abuso." 28

El control coercitivo de acuerdo a Stark es semejante a otras conductas delictivas como el secuestro y el acoso, en el sentido que es una conducta que se extiende temporalmente y que sus perpetradores usan para humillar a sus víctimas. Estas técnicas consisten normalmente en amenazar, explotar, y aislar al otro ${ }^{29}$. Tal como la víctima de estos delitos, las personas que son objeto de control coercitivo se encuentran frecuentemente sin acceso a dinero, comida, medios de comunicación y son obligadas a romper sus lazos con amigos y familia. A diferencia de estos delitos:

"[...] el control coercitivo es personalizado, se extiende a través del espacio social así como a lo largo del tiempo, y tiene un género en el sentido de que basa su impacto en la vulnerabilidad de las mujeres en tanto mujeres en razón de la desigualdad sexual. Otra diferencia es su finalidad. Los hombres implementan el control coercitivo para asegurar privilegios que involucran el uso del tiempo, el control de los recursos materiales, el acceso

27 STARK, Evan, Coercive Control: The Entrapment of Women in Personal Life, Oxford and New York: Oxford University Press, 2007, p. 104.

${ }^{28}$ STARK, Coercive Control, cit. nota ${ }^{\circ} 26$, p. 5.

${ }^{29}$ STARK, Coercive Control, cit. nota ${ }^{\circ} 26$, p. 5. 
al sexo y el servicio personal. Al igual que las agresiones, el control coercitivo socava la integridad física y psicológica de la víctima. Pero el principal medio utilizado para establecer el control es la microrregulación de los comportamientos cotidianos asociados con los roles femeninos estereotipados, como la forma en que las mujeres se visten, cocinan, limpian, socializan, cuidan a sus hijos o se desempeñan sexualmente. Esto se logra aprovechando los beneficios que las mujeres obtienen de su nueva igualdad, por ejemplo, tomando el dinero que ganan y las desventajas que sufren debido a la persistente discriminación sexual en el mercado y su sujeción a roles domésticos predeterminados. Estas dinámicas dan al control coercitivo un papel en la política sexual que lo distingue de todos los demás delitos." ${ }^{30}$

Aparece entonces que las conductas constitutivas de control coercitivo son conductas de violencia y que se corresponden con la explicación feminista: el control coercitivo es característicamente ejercido por el hombre contra su pareja y puede manifestarse en otros tipos de actos de violencia que privan, por razones de género, de opciones fundamentales a las personas. Si bien el control coercitivo normalmente involucra actos de violencia física, también puede tratarse de conductas menos lesivas pero tremendamente invasoras en la vida de las personas. Puede en efecto, tratarse de violencia psicológica, emocional, económica, religiosa y otras formas de violencia que van evolucionando en el tiempo. Por ejemplo, conductas que implican invadir por completo la privacidad del otro, o restringir su capacidad económica, o el aprovechamiento de la sexualidad del otro incluso con su voluntad, son todas conductas que pueden constituir control coercitivo cuando tienen por finalidad someter y dominar al otro. Estos actos pueden re-describirse como diversos tipos de violencia que se explican por la sociedad patriarcal y que al mismo tiempo tienen como efecto el reforzamiento, la mantención o reproducción de la sociedad patriarcal. Bajo la concepción de un Derecho Penal limitado, si parece legítima su intervención en casos especialmente graves, en otras palabras, cuando cierto tipo de actos de violencia refuerzan, mantienen o reproducen la sociedad patriarcal. Es decir, actos de violencia patriarcal que constituyen control coercitivo.

\section{La violencia patriarcal y la ley de Violencia Intrafamiliar}

Hasta este punto he tratado de argumentar en favor del término género para comprender las diferencias entre las distintas identidades individuales y el impacto que esta concepción tiene para poder identificar ciertas injusticias estructurales que aquejan desigualmente a ciertas partes de la población. En base a la noción de género he desarrollado una definición de patriarcado que nos permite identificar ciertos tipos de pérdida de opciones fundamentales y que se explican en la existencia de una sociedad patriarcal. En las últimas dos secciones he concebido un enfoque amplio sobre la violencia, y como se puede entender la violencia que priva de opciones fundamentales para las personas como violencia patriarcal. Así mismo, adopté la propuesta original de Michael Johnson y modificada por Evan Stark para identificar qué casos pueden entenderse específicamente como aquellos que viene explicados por la existencia de una sociedad patriarcal. Es precisamente este tipo de casos los que idealmente deberían estar bajo la regulación del control penal, puesto que se trataría de aquellos especialmente graves y por lo tanto donde

\footnotetext{
${ }^{30}$ STARK, Coercive Control, cit. nota n ${ }^{\circ} 26$, p. 5.
} 
se espera que el Derecho Penal contribuya legítimamente. Ahora bien, ya que este trabajo consiste en una contribución preliminar solo podré examinar con cierta profundidad un aspecto de la criminalización de las relaciones familiares, el bien jurídico protegido. En nuestro contexto chileno la norma que fundamentalmente criminaliza las relaciones familiares es el art. 14 de la ley 20.066, el que dispone lo siguiente:

Artículo 14.- Delito de maltrato habitual. El ejercicio habitual de violencia física o psíquica respecto de alguna de las personas referidas en el artículo $5^{\circ}$ de esta ley se sancionará con la pena de presidio menor en su grado mínimo a medio, salvo que el hecho sea constitutivo de un delito de mayor gravedad, caso en el cual se aplicará sólo la pena asignada por la ley a éste.

Para apreciar la habitualidad, se atenderá al número de actos ejecutados, así como a la proximidad temporal de los mismos, con independencia de que dicha violencia se haya ejercido sobre la misma o diferente víctima. Para estos efectos, no se considerarán los hechos anteriores respecto de los cuales haya recaído sentencia penal absolutoria o condenatoria.

En Chile, este delito tradicionalmente ha sido comprendido como una forma especial del delito de lesiones, pero me parece que esta conclusión podría ser apresurada en consideración al tipo de fenómeno que regula la Ley VIF, el que tal como lo hemos visto, es uno que viene caracterizado por la existencia de violencia patriarcal. En la actualidad no hay demasiados estudios que aborden en profundidad el problema de identificar el bien jurídico protegido. Sin demasiada justificación, la doctrina dominante se inclina por considerar que el bien jurídico protegido por el art. 14, ya que se trata de una forma especial de lesiones caracterizada por el contexto intrafamiliar, es la salud o la integridad corporal. Jean Pierre Matus y Cecilia Ramírez se inclinan por entender que el bien jurídico protegido es la salud individual ${ }^{31}$, asimismo Garrido Montt ${ }^{32}$ y Alex Van Weezel ${ }^{33}$. De los precedentes, Alex Van Weezel, sin embargo, es uno de los que más ha profundizado en la estructura de este delito. Un breve comentario sobre su posición aclarará que en principio no parece satisfactorio el estado actual de la discusión sobre el bien jurídico protegido por los delitos que criminalizan las relaciones familiares.

Lo siguiente no es una crítica general a la posición de Van Weezel, sino que pretendo utilizar su estudio para el propósito más general de criticar ciertas implicancias que se siguen de concebir al delito del art. 14 simplemente como un delito especial de lesiones o maltrato, revelando lo insuficiente de concebirlo de esta manera. Con respecto a la estructura del delito de violencia intrafamiliar, a Van Weezel le llama la atención el

31 MATUS, Jean Pierre; RAMIREZ, María Cecilia; Manual De Derecho Penal Chileno Parte Especial, Valencia: Tirant Lo Blanch, 2018, p. 115.

${ }^{32}$ MONTT, Garrido, Derecho Penal Parte Especial, Santiago: Editorial Jurídica de Chile, 2010, pp. $169-167$.

${ }^{33}$ VAN WEEZEL, Alex, "Lesiones y Violencia Intrafamiliar", Revista Chilena de Derecho, no 35 (2008), pp. 226-231. Para una interesante diferenciación entre salud e integridad corporal véase RETTIG, Mauricio, Análisis comparativo del tipo básico del delito de lesiones en España y en Chile. Bases para una reforma, Barcelona: Tesis Doctoral, Universitat de Barcelona, 2010, pp. 65-79, quien en lo fundamental argumenta que la integridad corporal no puede reducirse a la salud. Según Rettig cabe distinguir al menos 4 tipos de bienes jurídicos protegidos por el sistema de delitos de lesiones: (i) el derecho a la integridad física (ii) el derecho a la salud (física y mental) (iii) el bienestar psíquico y físico (iv) y la apariencia personal. 
contexto mismo de violencia intrafamiliar y sus efectos. A este respecto, parece afirmar que todo hecho descrito por alguna norma de la parte especial o en leyes especiales que implique violencia psíquica o física y que tenga lugar en el contexto intrafamiliar, es por definición violencia intrafamiliar en el sentido del art. 5, y por lo tanto hace aplicable (no el art. 14) los mecanismos de protección en favor de las víctimas, como por ejemplo, la prohibición de acuerdos reparatorios:

"[...] la violencia intrafamiliar con relevancia penal comprende tanto el delito de maltrato habitual -tipificado en la misma ley-como cualquier otro delito tipificado en el Código Penal o en leyes especiales que pueda considerarse como una forma de maltrato que afecta a la vida o a la integridad física o psíquica de alguna de las personas relacionadas con el autor en los términos del art. $5^{\circ}$ la Ley $\mathrm{N}^{\circ} 20.066$. Existiendo esta relación, constituyen por lo tanto violencia intrafamiliar los delitos de injurias, de abandono de niños o personas desvalidas, de lesiones, de violación, de robo con violencia, etc." ${ }^{34}$

Van Weezel concluye que el contexto intrafamiliar es un elemento "emergente" del tipo, precisamente porque implica calificar al hecho como violencia intrafamiliar independientemente que concurra en la especie el art. 14. Ahora bien, esta conclusión podría ser acertada si la premisa es correcta, esto es, que el bien jurídico protegido es algo así como la "vida familiar". Si el bien jurídico es la vida familiar, entonces quizás los hechos que deben considerarse merecedores de censura penal, deberían ser aquellos que lesionan o ponen en peligro la "vida familiar". Sin embargo, esta no es la concepción a la que recurre Van Weezel, sino la concepción que considera que se trata de una forma especial de delito de lesiones. Pero si el bien jurídico es la salud o la integridad corporal, entonces no parece justificado extender, sin algún argumento adicional, el tratamiento del art. 5 a casos en que lo protegido no hace referencia a la vida familiar. Ciertamente, la interpretación de Van Weezel permitiría considerar "intrafamiliar" delitos en los que propiamente se resguarda una relación meramente formal de familia, donde entonces, la explicación de dicha violencia y su contexto no serían relevantes. Es decir, si la Ley VIF se aplica a relaciones formalmente familiares, donde hay vínculos de familia que nunca se han hecho efectivos, entonces la Ley VIF debería interpretarse como una respuesta a un simple fenómeno de violencia independientemente de su contexto, no como un fenómeno de violencia que afecta desproporcionadamente a sujetos vulnerables y que tiene una causa particular. Esto tendría una consecuencia adicional: La ley VIF debería ser comprendida como un fenómeno social excepcional en el marco de los cambios legislativos que se han sucedido en los países alrededor del mundo respecto de como afrontar la violencia de género. En efecto, nuestra legislación no podría entenderse como parte del proceso más amplio de trasladar hacia la esfera pública hechos considerados previamente como de carácter privado, ni como una reivindicación de los movimientos que perseguían (y persiguen) como finalidad reducir la violencia de género.

Hay dos razones que vuelven poco plausible sostener que la Ley VIF se fundamenta en la protección de las personas independientemente del contexto en que la violencia se produce. Primero, en atención a la comprensión de la evolución de las legislaciones destinadas a reducir las desigualdades de género. Toledo considera que hay tres olas sucesivas de

\footnotetext{
${ }^{34}$ VAN WEEZEL, "Lesiones", cit. nota no 32, p. 233.
} 
reformas en torno a la violencia de género, tendencia que es más o menos de carácter mundial, pero que ella considera específicamente en el ámbito hispano. La primera ola de reformas en el mundo hispano tuvo por objetivo derogar ciertas normas penales que eran abiertamente discriminatorias por razones de género. La segunda ola de reformas y que pueden coincidir en el tiempo, tuvo por objetivo adecuar la legislación vigente de modo de cambiar el entendimiento de los delitos sexuales no como delitos contra la moralidad social, sino como delitos contra la autonomía sexual. Una tercera ola de reformas se avocó directamente a prevenir la violencia de género, específicamente la violencia contra la mujer $^{35}$. Es en este marco que se sitúa nuestra Ley VIF. Segundo, la ley no puede interpretarse como si regulara la violencia independientemente del contexto, porque precisamente el significado de la violencia intrafamiliar hace referencia a injusticias que indudablemente van más allá del puro ejercicio de violencia y la lesión del cuerpo y la psiquis. La tardía regulación en Chile de la violencia intrafamiliar se explica en que su regulación siempre se consideró "controversial", porque implicaba la intervención del Estado en un ámbito familiar que, en ausencia de la intervención estatal, privatizaba o reducía a la esfera privada patrones cíclicos de desigualdad contra la mujer ${ }^{36}$, y que por lo tanto, como contexto, permitía describir la situación de la mujer como vulnerable ${ }^{37}$. En otras palabras, regular este ámbito privado implicaba reconocer la existencia de ciertas injusticias estructurales, y corregir dichas injusticias en este ámbito privado implicaba regular el acceso a la economía y al poder político de una clase de personas cuya localización estaba tradicionalmente reducida a la esfera privada. En otras palabras, el contexto intrafamiliar tiene un carácter político que no puede reducirse a la lesión de la integridad corporal o salud de las personas que lo integran.

En el fondo, lo controversial del contexto intrafamiliar reside en cómo su organización y regulación tiene consecuencias para el acceso a la economía y al poder político, al tiempo que también es fuente de bienestar para las personas. Si efectivamente la Ley VIF debe comprenderse como parte de este proceso más amplio cuya finalidad es reducir la violencia de género $^{38}$, específicamente la violencia contra la mujer comprendida como violencia patriarcal, aunque sin excluir otro tipo de violencia, entonces aparece insuficiente concebir al bien jurídico protegido como la salud o la integridad corporal sin mayor argumento. Parece necesario algún argumento adicional que permita explicar el plus de injusto que justifique una agravación del tratamiento procesal que se sigue de interpretar un hecho con arreglo al art. 5 de la Ley VIF y asimismo, que justifique la existencia misma del art. 14. Esto no significa negar que el art. 5 podría ser efectivamente un elemento emergente, pero la condición para su aplicación no sería el mero hecho que el contexto es intrafamiliar, en el sentido de constituir una relación formal de familia.

\footnotetext{
${ }^{35}$ Véase el panorama en VASQUEZ, Patsili, Femicidio, Mexico: Naciones Unidas, 2009, Capítulo 3.

${ }^{36}$ OKIN, Susan, Justice, Gender, and the Family, New York: BasicBooks, 1989, Capítulo 6.

${ }^{37}$ HONNETH, Axel, "Between Justice and Affection: The Family as a Field of Moral Disputes", en HONNETH, Axel, Disrespect: The Normative Foundations of Critical Theory, Cambridge: Polity Press, 2007, p. 149

${ }^{38}$ Así lo comprende también CASAS, "La respuesta", cit. nota $\mathrm{n}^{\circ}$ 5, p. 135; también RAMIREZ, Maria Cecilia, "Delitos de parricidio-parricidio-feticidio y la ley de Violencia Intrafamiliar", en: MALDONADO, Francisco, (eds.) Reformas Penales, Santiago: Ediciones DER, 2017, p. 278; también la interpreta de esta manera, aunque críticamente CARNEVALI, Raúl, "Derecho penal como ultima ratio. Hacia una política criminal racional", Ius Et Praxis, n 14 (2008), p. 37
} 
Quien más ha profundizado en el bien jurídico protegido por la Ley VIF ha sido Myrna Villegas en un ensayo del año 2012. Villegas estima errada la interpretación que considera que el bien jurídico protegido por el tipo del art. 14 de la ley VIF es la integridad corporal o la salud. Para Villegas lo realmente protegido por el legislador sería la dignidad de la persona. La argumentación de la autora es interesante y merece ser reproducida aquí:

"Tomando posición a este respecto, se estima que si bien en un contexto de VIF los bienes jurídicos afectados pueden ser varios, en atención a las diversas conductas que se cometan (lesiones, amenazas, etc.) no es éste su rasgo distintivo, pues, como se ha dicho, tiene un plus de injusto que excede a los delitos comunes y que vendría dado por la existencia de abuso de poder por parte del agresor hacia personas especialmente vulnerables[...]

Por ello es que el bien jurídico afectado en esta clase de conductas no puede ser otro que la dignidad de la persona humana y su integridad moral." 39

De acuerdo a la tesis que sostengo en este trabajo esta interpretación es parcialmente correcta, porque se corresponde, como hemos visto, con el tipo fenómeno de violencia que es explicado por la existencia de una sociedad patriarcal. Este es un punto fundamental, porque implica la adopción del punto de partida que considero fundamentalmente correcto: reconocer que hay una situación de abuso de poder. Ciertamente parece acertado entender que hay algo diferente cumpliendo un rol justificativo de la criminalización de la violencia intrafamiliar, y que no queda suficientemente capturado por la concepción de esta violencia como un caso especial de lesiones. En efecto, en principio, si el bien jurídico protegido es la integridad corporal o la salud, se trataría de un bien jurídico instrumental, y por lo tanto, podría ser objeto de disposición si el titular consiente en ello. Pero si esta fuera la justificación del art. 14, entonces quedaría sin explicación la prohibición del art. 19 de la ley VIF que establece que "En los procesos por delitos constitutivos de violencia intrafamiliar no tendrá aplicación el artículo 241 del Código Procesal Penal." En efecto, si el bien jurídico protegido es susceptible de disposición por parte de su titular, entonces con mayor razón podría consentir en un acuerdo reparatorio. Sin embargo, si lo protegido consiste en la "dignidad" de la persona, entonces en principio no cabe la disposición por parte del titular: la persona no puede disponer de su dignidad ${ }^{40}$.

Una respuesta alternativa a la dignidad como bien jurídico protegido, y que explica que es aquello que expone a la mujer en una posición especial de vulnerabilidad, es considerar la existencia misma del contexto intrafamiliar. Nótese que el ejecutivo señaló en su momento que lo protegido era la "sana y adecuada constitución familiar" y que la violencia constituía "un factor de riesgo para la integridad física, psíquica o sexual de sus demás integrantes"

\footnotetext{
${ }^{39}$ VILLEGAS, Myrna, "El delito de maltrato habitual en la Ley No 20.066 a la luz del derecho comparado", Política Criminal, $\mathrm{n}^{\circ} 7$ (2012), p. 292 (las cursivas resaltadas en el texto son mías).

${ }^{40}$ Para un argumento en este sentido véase DAN-COHEN, Meir, "Dignity, Crime, and Punishment: A Kantian Perspective", en: DUBBER, Marcus, (ed.), Foundational Texts In Modern Criminal Law, Oxford: Oxford University Press, 2014, pp. 101-119. Básicamente, Dan-Cohen elabora su argumento considerando que no podríamos estimar que el esclavo "feliz", que habitaba el sur de Estados Unidos durante el siglo XIX, ha decidido autónomamente ser un esclavo, aunque sea un esclavo "feliz".

41 "Primer Informe de la Comisión de Familia", en Historia de la Ley $N^{\circ} 20.066$, p. 86, en: www.bcn.cl [visitado el 10.12.2018].
} 
Sin embargo, el factor crítico es identificar el contexto que implica para la mujer correr un riesgo predecible de ser objeto de violencia. Esta línea argumentativa habría llevado al legislador a considerar el mismo contexto intrafamiliar, la familia, como la circunstancia que explica la mayor posición de vulnerabilidad para la mujer. Ahora bien, si se trata de resguardar el interés de la mujer, entonces pareciera mejor establecer dispositivos para prevenir que la mujer se localice en dichos contextos intrafamiliares. Pero entonces, pareciera que el constituyente ha concebido incorrectamente a la familia como un bien a resguardar.

En efecto, si la vida familiar como contexto íntimo es un contexto que somete a la mujer al riesgo desigual de sufrir actos de violencia, entonces parece sospechoso valorar y promover la creación de dichos contextos. Sin embargo, esta interpretación es errada, aunque sea verdadero caracterizar el contexto intrafamiliar como un contexto riesgoso y aunque sea verdadero que la familia es también una fuente de bienestar. Lo que perseguía el ejecutivo era apelar a una interpretación conservadora sobre los valores tradicionales como la familia, pero esto tampoco puede ser correcto. No es reconciliable la idea que el bien jurídico protegido es la sana vida familiar con la idea que el contexto intrafamiliar constituye una posición de vulnerabilidad para la mujer, hecho que la evidencia empírica parece haber establecido con cierta certeza. Tampoco la noción de sana vida familiar es reconciliable con la estructura de la Ley VIF, porque las medidas que contempla la ley son mecanismos que tienden inequívocamente a proteger los intereses de la víctima y no el interés de la "institución de la familia". Esto es suficiente para rechazar esta interpretación. Sin embargo, concebir la dignidad como el bien jurídico protegido tampoco puede ser una interpretación completamente correcta, precisamente porque deja abierta la pregunta acerca de aquello que hace especialmente vulnerable a la mujer. Si la premisa es la existencia de una relación desigual de poder, la conclusión que el bien jurídico protegido es la dignidad no parece explicar efectivamente porque la mujer es especialmente vulnerable dentro del contexto intrafamiliar. Esta interpretación, como puede verse, tiene el mismo problema que aquella concepción examinada en la sección 3 de este ensayo, porque tampoco conecta la violencia con la existencia de la sociedad patriarcal.

\section{La violencia patriarcal y la protección de la mujer}

Aparece una tercera alternativa y que la doctrina chilena todavía no ha considerado ni elaborado con rigurosidad; la existencia de una sociedad patriarcal. Si bien en este trabajo preliminar no ofreceré una elaboración completamente acabada del bien jurídico protegido por la Ley VIF y la completa especificación de sus implicaciones, si he desarrollado suficientemente sus bases como para una formulación general de una concepción. Esta concepción comienza por donde Villegas termina, porque su concepción no alcanza a desarrollar la conexión entre la violencia que describe la posición de la mujer en el contexto intrafamiliar como desigual, y por ende vulnerable, y la existencia de la sociedad patriarcal. La propuesta sobre el injusto adicional que fundamenta la intervención del Derecho Penal está vinculada con la existencia de la violencia patriarcal y la privación de opciones fundamentales que tiene como consecuencia. Más específicamente, en la medida que un acto de violencia al interior de la familia puede comprenderse como un acto de violencia 
patriarcal, tal acto contribuye a reproducir o mantener una sociedad patriarcal ${ }^{42}$ y por lo tanto priva de opciones fundamentales a las que de otro modo dicha persona tendría acceso. Aquellos actos de violencia que reproducen o mantienen la sociedad patriarcal privan de opciones fundamentales a cierta parte de la población, y ya que estas son opciones fundamentales cuya privación tiene lugar de una manera especialmente violenta, se justifica la intervención del Derecho Penal.

Para este enfoque el bien jurídico protegido serían las opciones fundamentales que una persona tiene para conseguir éxito en su vida, lo que básicamente se traduce en el disfrute de la libertad negativa, entendida como la libertad de elegir la vida que la persona quiere vivir libre de interferencias arbitrarias ${ }^{43}$. Este derecho básico de la persona, comúnmente entendido también como parte del concepto de autonomía personal, tiene recepción constitucional tanto en la forma del derecho general a la libertad y seguridad como en el derecho a la privacidad. Y sin duda su disfrute y ejercicio se ve gravemente afectado por la existencia de una relación afectiva en la que el sujeto activo persigue controlar y dominar al sujeto pasivo a través de la violencia psíquica y física, manifestando de tal modo una relación afectiva que mantiene una sociedad patriarcal. Como parece obvio, estos actos de violencia patriarcal son precisamente aquellos a los que se refiere Stark, es decir, aquellos en que existe un sujeto que emplea la violencia física o psíquica como parte de una estrategia más general de poder y control sobre otra persona. También se trata precisamente de aquellos actos de violencia a los que se refiere Madden Dempsey, es decir, aquellos que se explican en la existencia de una estructura social injusta, la descripción de una sociedad como una sociedad patriarcal, y que adicionalmente mantienen la descripción de una sociedad como patriarcal. La conclusión entonces, es que la Ley VIF debería comprenderse como una estrategia particular del orden penal para reducir o disminuir el carácter patriarcal de la sociedad de la que la relación afectiva es parte.

Ya hemos visto los problemas que enfrenta la posición de la integridad corporal y la dignidad como posibles bienes jurídicos, los que no enfrenta la propuesta ya desarrollada. Sin embargo, la tesis propuesta no está exenta de problemas. Hay varios desafíos y problemas generales que la propuesta debe poder responder para ser concluyente y que van más allá de responder satisfactoriamente a la justificación por el plus de injusto de la criminalización de conductas de violencia al interior de la familia. La presente propuesta sobre el bien jurídico, sin embargo, no está sujeta al problema que la descripción del tipo

\footnotetext{
${ }^{42}$ DEMPSEY, Prosecuting, cit. nota $n^{\circ} 21$, p. 123-124.

${ }^{43}$ Utilizo el término "arbitrario" porque mi intención es dejar abierta la cuestión de cómo mejor caracterizar la libertad afectada: o bien caracterizarla en un sentido liberal, o bien en un sentido republicano. Entendida en el primer sentido, la libertad que se pierde a consecuencia de la violencia patriarcal no es más ni menos que la libertad de ser objeto de un constreñimiento a hacer algo a lo que una persona no está obligada. Entendido en el segundo sentido, la libertad que se pierde a consecuencia de la violencia patriarcal es la libertad de la persona de no estar sujeta a interferencias arbitrarias que se originan en la conducta del otro. Ambos conceptos de libertad son distintos y se justifican en un ideal político de libertad distinto: el primero está asociado a la noción de libertad liberal individual, y la segunda a la noción de ciudadanía. Para una interpretación de la libertad liberal aplicada al Derecho Penal, véase MOORE, Michael S, "Liberty's Constraints on What Should be Made Criminal", en: DUFF, R.A. et al, (eds.), Criminalization: The Political Morality of the Criminal Law, Oxford: Oxford University Press, 2014, pp. 182-213. Para una interpretación republicana véase PETTIT, Philip, "Republican theory and criminal punishment", Utilitas, no 9 (1997), pp. 59-79.
} 
no lo recepciona en algún sentido importante. En efecto, uno de los contra-argumentos principales que podría formularse en contra de la presente comprensión del bien jurídico, es que aparentemente si bien es verdadero que sólo el tipo de violencia constitutiva de control coercitivo expresaría la violencia patriarcal, la Ley VIF no haría esta distinción. En otras palabras, la ley sancionaría en principio cualquier forma general de violencia que cuente como habitual, lo que incluiría ciertamente el control coercitivo, pero también la violencia situacional, violencia que, como hemos visto, ni perpetúa la sociedad patriarcal ni estaría explicada por este tipo de sociedad. La conclusión alteraría la forma de comprender la ley VIF, en el sentido que si la conclusión fuera correcta, entonces se seguiría que la ley no estaría encaminada a evitar la perpetuación del patriarcado. Esto es, sin embargo, un error.

Es cierto que nuestra ley VIF no parecería distinguir apropiadamente los casos de violencia propiamente situacional de los casos de control coercitivo, sin embargo, esto no significa que los casos de control coercitivo no estén efectivamente siendo objeto del Derecho Penal: ello solamente quiere decir que no se han identificado claramente los casos. El problema entonces consiste en que el tipo no distingue claramente entre ambas situaciones, pero no que el bien jurídico no sea operativo. Ahora, si bien la distinción no se sigue claramente de la ley, la noción de control coercitivo permite distinguir una serie particular de casos que quizás no han sido todavía comprendidos como especialmente graves, y para los que la ley no ha establecido criterios demasiado precisos. A estos casos graves, que integran la violencia situacional, respondería la noción de control coercitivo. Como hemos visto, la ley VIF no sanciona solamente la violencia física, sino que también incluye la violencia psíquica cuando ambas se ejercen de manera habitual. Ahora bien, parece posible considerar que los casos de control coercitivo, en el que el ejercicio de violencia está destinado a controlar la vida de la otra persona, para interpretar los casos especialmente graves y que justifican la aplicación del art. 14 a los casos de violencia psíquica. Desde este punto de vista, habría al menos dos clases de violencia psíquica que pueden distinguirse. Una clase tiende a entenderse restrictivamente como actos de coacciones o amenazas en que lo que es sobresaliente es la conducta violenta de quien la ejerce. Villegas demuestra con algunos casos en la jurisprudencia de la Corte Suprema, que este es efectivamente un criterio para determinar una clase de violencia psíquica constitutiva de maltrato habitual.

Sin embargo, esta no es la única clase de violencia psíquica. Como demuestra la evidencia científica, los efectos a largo plazo de la violencia psíquica son devastadores desde el punto de vista del derecho a una persona a vivir la vida que quiere vivir| y los que tienen su origen en actos de violencia psíquica menos evidentes. Desde este punto de vista hay ciertos actos más silenciosos o menos llamativos, en que la conducta no parece propiamente violenta en atención a la conducta desplegada pero que si constituyen instancias de control coercitivo. Aquí en principio hay una distinción que hacer. Actos que se extienden en el tiempo como el control de las relaciones afectivas con amigos, limitación de las interacciones familiares, control del presupuesto, sin duda sí deben ser considerados como violencia patriarcal cuando son parte de un patrón de conducta que constituye control coercitivo. Los tribunales pueden elegir qué estrategia adoptar y por ende podrían considerar únicamente punible como violencia psíquica atendiendo a las propiedades de la conducta. Pero esto desconocería el impacto que tiene el control coercitivo en la vida de las personas, el que muchas veces priva de más bienestar que aquellos comportamientos que se consideran 
violentos en atención a la mera conducta. Una interpretación que pretenda reducir la violencia patriarcal y la sociedad patriarcal en la que dicha violencia tiene origen, debería seleccionará una vía interpretativa admisible por el cuerpo legal y que discrimine aquellos casos especialmente graves de violencia psíquica y en los que concurre el plus de injusto que justifica su criminalización ${ }^{44}$.

Una última crítica que quiero considerar explota precisamente el hecho que la justificación de la sanción que ofrezco parece beneficiar exclusivamente a las mujeres, después de todo, son ellas la que se encuentran en una posición de vulnerabilidad debido a la existencia del patriarcado. La crítica considera que si ello es efectivo, la Ley VIF, sin embargo, adopta un lenguaje neutral que no diferencia por género, y en consecuencia, no sólo la protección se debilita simbólicamente, sino que se asientan dudas que el bien jurídico sea realmente el que he propuesto. Mi posición al respecto no es definitiva, pero creo, en principio, que es una virtud de la legislación que adopte un lenguaje neutral que no distinga el género ni de la víctima ni del autor. Esto no impide que la legislación responda a la violencia patriarcal, porque ello supondría considerar correcto el poco plausible punto de vista que considera que desplegar una "conducta patriarcal" depende del sexo del autor. En efecto, esto involucraría adoptar la perspectiva del determinismo biológico que he considerado errada. Por lo demás, adoptar un lenguaje neutral evita discriminaciones injustificadas. Este es precisamente uno de los problemas de la regulación española que explícitamente adopta un lenguaje no neutral ${ }^{45}$, porque al centrarse en una definición de violencia doméstica como violencia heterosexual donde es el hombre el más fuerte y grande naturalmente, construye la violencia doméstica como violencia heterosexual, dejando de lado la situación de aquellas/os cuya identidad no cabe tradicionalmente entenderla como parte del sexo femenino, y que por lo tanto aparecen injustificadamente excluidas/os del ámbito de aplicación de la ley $\mathrm{VIF}^{46}$.

Quizás lo que parece contra-intuitivo de mi propuesta es que en principio, ya que la legislación no protege exclusivamente a la mujer, en razón de no utilizar un lenguaje neutral, la mujer podría eventualmente ejecutar actos de terrorismo doméstico ${ }^{47}$ o control coercitivo. Pero, si la mujer es precisamente la víctima de una sociedad patriarcal, entonces, ¿Cómo puede considerarse al mismo tiempo como responsable del fenómeno de tal estructura social injusta? Ciertamente, se sigue de mi propuesta, que la conducta de la

\footnotetext{
${ }^{44}$ Esta interpretación también podría justificar la interpretación de Van Weezel sobre el art. 5 de la ley VIF, siempre, claro está, que se trate de casos de control coercitivo.

${ }^{45}$ Para una defensa de las leyes penales contra la violencia de género no neutrales véase en el ámbito español LARRAURI, Elena, "Igualdad y violencia de género", Indret: Revista para el Análisis del Derecho, n 1 (2009) http://www.indret.com/pdf/597.pdf [visitado el 03.01.2019]; para una panorámica general sobre la regulación penal de la violencia de género y doméstica en España, véase MUÑOZ CONDE, Francisco, Derecho Penal Parte Especial, Valencia: Tirant Lo Blanch, 2015, pp. 175-186.

${ }^{46}$ DEMPSEY, Brian, “Trans People's Experience of Domestic Abuse”, SCOLAG Legal Journal, no 396 (2010). Cabe notar, en cualquier caso, que el uso de lenguaje no neutral no impide que la explicación la violencia recurra a teorías feministas como la noción de patriarcado, ni tampoco impide que sea precisamente dicha explicación la que se utilice como base para una determinada regulación penal de cierto tipo de interacción social, como las interacciones familiares.

${ }^{47}$ De ello parece haber alguna evidencia, véase HINES, Denise; DOUGLAS, Emily, "Intimate terrorism by women towards men: does it exist?", Journal of Aggression, Conflict and Peace Research, n 2 (2010), pp. 36-56.
} 
mujer puede perpetuar el patriarcado en la medida que su conducta constituya control coercitivo. Si bien esto está en conformidad con la comprensión que "todos" tienen razones para ser feministas, que creo fundamentalmente correcta, porque la violencia afecta a todos aunque no sea por igual, ello no disminuye lo contra-intuitivo de la propuesta. Debo confesar aquí, que no obstante la propuesta sea en este aspecto contra-intuitiva no la hace menos plausible. No creo que pueda aceptarse que es el solo hecho biológico de ser hombre sea lo que vuelve a la sociedad una sociedad patriarcal. Lo que transforma una sociedad en una sociedad patriarcal son las estructuras sociales injustas, las que se mantienen y promueven en parte por las prácticas familiares de violencia que persiguen controlar y dominar a la pareja. Desde este punto de vista, la conducta constitutiva de control coercitivo por parte de la mujer parece poder se descrita, en ciertos casos, como aquella que perpetúa la violencia patriarcal. En estos casos la mujer parece ser "instrumentalizada por la sociedad patriarcal" en el sentido que es doblemente víctima del patriarcado: primero, porque adopta el modelo de pareja que despliega una conducta de control coercitivo, y segundo porque dicho despliegue de conducta la hace ingresar al ámbito de la intervención penal. A pesar de ello, creo que en la medida que contribuye con su conducta al patriarcado, la persona que despliega un comportamiento controlador coercitivo, independientemente de su género, parece no sólo ser víctima, sino también, en principio, responsable por el injusto que realiza ${ }^{48}$.

\section{Conclusión}

Todos estos problemas son puntos claves para una evaluación concluyente de la propuesta teórica que he desarrollado en este trabajo, sin embargo revisando sus fundamentos y respondiendo a algunas de los contra-argumentos más importantes, sobre todo en relación a las propuestas alternativas que no están exentas de problemas, pareciera que la propuesta es, al menos, plausible. La siguiente etapa conducente a desarrollar esta propuesta, requeriría profundizar en muchos aspectos que no han podido ser abordados aquí ${ }^{49}$.

\footnotetext{
${ }^{48}$ Empleo que el término responsabilidad en sentido amplio, porque no desconozco la posibilidad que el injusto pueda verse reducido por la culpabilidad por el hecho. Como he insistido a lo largo de este trabajo, estas son conclusiones preliminares que, si bien todavía no puede considerarse concluyentes si, no obstante, se apoya en razones que la hacen plausible.

${ }^{49}$ Hay al menos trece aspectos clave que un estudio completo sobre la temática debería desarrollar, algunos de los cuales ya han sido abordados por la literatura chilena. Primero, que tipos de aspecto del agente individual va a ser objeto del Derecho Penal: ¿sus acciones intencionales, o su carácter y motivaciones?; segundo, que objetos el Derecho Penal debe considerar como impermisibles: ¿acciones individuales no permisibles, o estructuras sociales injustas?; tercero, que tipo de justificación se va a emplear para legitimar al derecho penal: ¿la realización de daños individuales o daños colectivos?; quinto, que tipo de exigencias subjetivas debe satisfacerse para la realización del tipo: ¿se castiga las acciones dolosas o imprudentes?; sexto, determinar el fundamento que permite prohibir la procedencia de acuerdos reparatorios: ¿puede presumirse siempre la vulnerabilidad de la víctima y privarle el estado la posibilidad de negociar su propia solución?; séptimo, y relacionado con lo anterior: ¿hay excepciones al trato de incapaz que supone la prohibición de acuerdos reparatorios?; octavo, examinar la problemática situación de la criminalización de la mujer vulnerable; noveno, determinar las ventajas de la neutralidad del lenguaje frente en consideración a las parejas del mismo sexo, y la situación de los/las intersexuales, transgénero y transexuales; décimo, un examen pormenorizado del tipo de tratamiento de justicia restaurativa que se imparte y su efectividad; undécimo, los problemas de prueba de los hechos; duodécimo, una respuesta sistemática a las objeciones sobre el uso del término patriarcado para explicar la violencia de género; trigésimo, una respuesta fundamentada a la pregunta si la conducta de la mujer puede perpetuar el patriarcado.
} 
Fundamentalmente, realizar un estudio pormenorizado de la jurisprudencia para detectar que casos de acuerdo a la jurisprudencia de los tribunales chilenos muestran una conexión entre sociedad patriarcal y violencia patriarcal, casos que se consideren especialmente graves y susceptibles de censura penal. Desde luego, esto no significa que la propuesta, hasta este punto, no pueda contribuir desde ya a un debate de lege ferenda. Ciertamente parece apropiado, por decir lo menos, que la legislación distinga apropiadamente las diferentes formas de violencia, y en sus medidas, posiblemente, destine las más severas cuando se trate de hechos efectivamente lesivos de intereses relevantes para las personas. La propuesta, si bien implicaría mayor criminalización formal de conductas que quizás no estén suficientemente sometidas al escrutinio de los tribunales, no descansa en una confianza injustificada en el sistema penal. Sin embargo, la evidencia y la experiencia comparada muestra que si bien la herramienta penal puede ser necesaria para regular ciertos casos especialmente graves, no es suficiente. Se requieren de otro tipo de medidas, algunas de carácter más terapéutico en la esfera civil y propiamente de familia, y la existencia de medidas no solamente resocializadoras sino de justicia restaurativa. La protección de la libertad negativa de las víctimas de la violencia patriarcal también requiere de prestaciones específicas que ayuden a reconstruir y posibilitar la libertad positiva de quienes han sufrido este tipo de violencia. 


\section{Bibliografía}

ALEXY, Robert, Teoría de los Derechos Fundamentales, Madrid: Centro de Estudios Constitucionales, 1993.

ACKER, Joan, "The Problem with Patriarchy", Sociology, no 23 (1989), pp. 235-240.

BUTLER, Judith, Gender Trouble: Feminism and the Subversion of Identity, London and New York: Routledge, 1990.

CAPALDI, Nicholas, “The Meaning of Equality”, en: MACHAN, Tibor (ed.), Liberty and Equality, California: Hoover Institution Press, 2002, 1-35.

CARNEVALI, Raúl, "Derecho penal como ultima ratio. Hacia una política criminal racional", Ius Et Praxis, no 14 (2008), pp. 13-48.

CASAS BECERRA, Lidia; VARGAS PAVES, Macarena, "La respuesta estatal a la violencia intrafamiliar", Revista de Derecho, no 24 (2011), pp. 133-151.

DAN-COHEN, Meir, "Dignity, Crime, and Punishment: A Kantian Perspective", en: DUBBER, Marcus, (ed.), Foundational Texts In Modern Criminal Law, Oxford: Oxford University Press, 2014, pp. 101-119.

DEMPSEY, Brian, "Trans People's Experience of Domestic Abuse”, SCOLAG Legal Journal, no 396 (2010), pp. 208-212.

DEMPSEY, Michelle Madden, Prosecuting Domestic Violence: A Philosophical Analysis, Oxford: Oxford University Press, 2009, p. 113.

ECKERT, Penelope; MCCONNELL, Ginet, Language and Gender, Cambridge: Cambridge University Press, 2003.

ELTIT, Diamela, Crónica del Sufragio Femenino en Chile, Chile: Servicio Nacional de la Mujer, 1994.

FAUSTO-STERLING, Anne, "Where does gender come from?", en KIMMEL, Michael; ARONSON, Amy, (eds.) The Gendered Society Reader, New York and Oxford: Oxford University Press, 2017, pp. 3-4.

FAUSTO-STERLING, Anne, Myths of Gender: Biological Theories About Women and Men, New York: BasicBooks, 1992.

GILLIGAN, Carol, In a Different Voice: Psychological Theory and Women's Development, Cambridge Mass: Harvard University Press, 1993.

HINES, Denise; DOUGLAS, Emily, "Intimate terrorism by women towards men: does it exist?” Journal of Aggression, Conflict and Peace Research, $\mathrm{n}^{\circ} 2$ (2010), pp. 36-56.

HONNETH, Axel, "Between Justice and Affection: The Family as a Field of Moral Disputes", en HONNETH, Axel, Disrespect: The Normative Foundations of Critical Theory, Cambridge: Polity Press, 2007, pp. 144-162.

HOWELL, Martha, Women, Production and Patriarchy in Late Medieval Cities, Chicago and London: Chicago University Press, 1986.

JOHNSON, Michael, "Patriarchal Terrorism and Common Couple Violence: Two Forms of Violence against Women", Journal of Marriage and Family, no 57 (1995), pp. 283294.

JOHNSON, Michael; LEONE, Janel, "The Differential Effects of Intimate Terrorism and Situational Couple Violence: Findings From the National Violence Against Women Survey", Journal of Family Issues, nº 26 (2005), pp. 322-349. 
JOHNSON Michael; LEONE, Janel; XU, Yili, "Intimate Terrorism and Situational Couple Violence in General Surveys: Ex-Spouses Required", Violence Against Women, $\mathrm{n}^{\circ}$ 20 (2014), pp. 186-207.

JORGENSEN, Gunnar, "Kohlberg and Gilligan: duet or duel?", Journal of Moral Education, $\mathrm{n}^{\circ} 35$ (2006), pp. 179-196.

KROLOKKE, Charlotte; SORENSEN, Anne; Gender Communication Theories and Analyses: From Silence to Performance, London: SAGE, 2006.

KUHN, Thomas, La Estructura de las Revoluciones Científicas, México: Fondo de Cultura Económica, 2013.

LARRAURI, Elena, "Igualdad y violencia de género", Indret: Revista para el Análisis del Derecho, $\mathrm{n}^{\circ} 1$ (2009), pp.1-17, http://www.indret.com/pdf/597.pdf [visitado el 03.01.2019].

LERNER, Geda, The Creation of Patriarchy, New York and Oxford: Oxford University Press, 1986.

MARTÍN SANCHEZ, María, "El género en la 'violencia afectiva': clave para un examen de constitucionalidad", Estudios Constitucionales, no 13 (2015), pp. 203-236.

MIKKOLA, Mari, The Wrong of Injustice: Dehumanization and Its Role in Feminist Philosophy, Oxford: Oxford University Press, 2016.

MIKKOLA, Mari, "Feminist Perspectives on Sex and Gender", en: ZALTA, Edward, (ed.) The Stanford Encyclopedia of Philosophy (Winter 2017 Edition) https://plato.stanford.edu/cgi-bin/encyclopedia/archinfo.cgi?entry=feminism-gender [visitado el 12.12.2018].

MOLTEDO, Cecilia; SILVA, Clotilde; ORELLANA, Silva; Estudio Sobre Violencia Doméstica en Mujeres Pobladoras Chilenas, Santiago: CUSO, 1989.

MATUS, Jean Pierre; RAMIREZ, María Cecilia; Manual De Derecho Penal Chileno Parte Especial, Valencia: Tirant Lo Blanch, 2018.

MONTT, Garrido, Derecho Penal Parte Especial, Santiago: Editorial Jurídica de Chile, 2010.

MOORE, Michael S, "Liberty's Constraints on What Should be Made Criminal", en: DUFF R.A.; FARMER, Lindsay; MARSHALL, S.E.; RENZO, Massimo; TADROS, Victor, (eds.) Criminalization: The Political Morality of the Criminal Law, Oxford: Oxford University Press, 2014.

MUÑOZ CONDE, Francisco, Derecho Penal Parte Especial, Valencia: Tirant Lo Blanch, 2015.

OKIN, Susan, Justice, Gender, and the Family, New York: Basic Books, 1989.

PETTIT, Philip, "Republican theory and criminal punishment", Utilitas, nº 9 (1997), pp. 59-79.

RAMIREZ, Maria Cecilia, "Delitos de parricidio-parricidio-feticidio y la ley de Violencia Intrafamiliar", en: MALDONADO, Francisco, (eds.) Reformas Penales, Santiago: Ediciones DER, 2017, p. 275-292.

RETTIG, Mauricio, Análisis comparativo del tipo básico del delito de lesiones en España y en Chile. Bases para una reforma, Barcelona: Tesis Doctoral, Universitat de Barcelona, 2010.

SACK, Emily, "Battered Women and the State: The Struggle for the Future of Domestic Violence Policy", Wisconsin Law Review, nº 6 (2004), pp. 1658-1739. 
STARK, Evan, Coercive Control: The Entrapment of Women in Personal Life, Oxford and New York: Oxford University Press, 2007.

SCHNEIDER, Elizabeth, Battered Women and Feminist Lawmaking, New Heaven: Yale University Press, 2000.

STOLLER, Robert, The Development of Masculinity and Femininity, London: Karnac Books, 1968.

VAN WEEZEL, Alex, “Lesiones y Violencia Intrafamiliar”, Revista Chilena de Derecho, no 35 (2008), pp. 223-259.

VASQUEZ, Patsili, Femicidio, México: Naciones Unidas, 2009.

VILLEGAS, Myrna, "El delito de maltrato habitual en la Ley $\mathrm{N}^{\circ} 20.066$ a la luz del derecho comparado", Política Criminal, no 7 (2012), pp. 276-317.

VAYRYNEN, Raimo, “Thick Ethical Concepts”, en: ZALTA, Edward, (ed.) The Stanford Encyclopedia of Philosophy (Fall $2017 \quad$ Edition) https://plato.stanford.edu/entries/thick-ethical-concepts/ [visitado el 12.12.2018].

WIESNER-HANKS, Merry, Gender In History: Global Perspectives, Chichester: WileyBlackwell, 2010. 